\title{
Study of Heat Transfer Characterstics With Geometry And Nanofluids
}

\author{
Authors \\ T.Satyanarayana ${ }^{1}$, V.Gowtham Reddy ${ }^{2}$ \\ Department of Mechanical Engineering, Vikas College of Engineering and Technology India \\ E-mail: thotasatya345@gmail.com, gowtham0419@gmail.com
}

\begin{abstract}
The growing demand for industry and automobile applications emphasizes on the equipment with best performance. Attaining best performance is the challenge kept to the researchers. One system where we can improve the quality by some modifications is heat exchanger. The heat transfer in the heat exchanger can be enhanced by introducing roughened surfaces such as ribs and grooves in the channel to disturb the flow and producing the vertices. In this project trapezoidal and triangular ribs and grooves are employed for the purpose. The trapezoidal and triangular ribs and grooves of various configurations are taken. The other way to enhance heat transfer is to employ nano fluids. Nano fluids are fluids that contain suspended nano particles such as metals and oxides. These nano particles keep suspended in the base fluid. In this three different types of nano particles, $\mathrm{Al}_{2} \mathrm{O}_{3}, \mathrm{SiO}_{2}$, and $\mathrm{ZnO}$ with different volumes fractions in the range of 1-4\% and different nano particle diameter in the range of 30-70 nm, have been also studied. Numerical simulation is the best way to get accurate results in less time. The present work is done with numerical simulation software FLUENT.
\end{abstract}

Keywords- heat exchangers, ribs and grooves, FLUENT, $\mathrm{AL}_{2} \mathrm{O}_{3}, \mathrm{SIO}_{2}$, $\mathrm{ZnO}$ nano fluids.

\section{INTRODUCTION}

There are many researchers who studied the forced convection heat transfer in a rib-groove channel [1]. Recently, researchers have shown an increase in forced convection heat transfer. Attempts have been made to enhance heat transfer in the heat exchangers by using roughened surfaces such as rib, groove and helical rib in disturbing the flow and in providing transverse/longitudinal vortices or three dimensional mixing [2]. There are many geometric shapes of the rib-groove channel which have been studied in the past. The common geometric shapes include rectangular, triangular, square, and circle [3-4]. All these types of rib-groove channels were used in many engineering applications such as cross-flow heat exchanger, gas turbine airfoil cooling design, solar air heater blade cooling system, and gas cooled nuclear reactor [5-6]. One of the ways to enhance heat transfer in the separated regions is to employ nano fluids [7-8]. Nano fluids are fluids that contain suspended nano particles such as metals and oxides [9]. These nano scale particles keep suspended in the base fluid. Thus, it does not cause an increase in pressure drop in the flow field [10]. Past studies showed that nano fluids exhibit enhanced thermal properties, such as higher thermal conductivity and convective heat transfer coefficients compared to the base fluid [11-12].

\subsection{Forced Convection Heat Transfer:}

Convection is the mechanism of heat transfer through a fluid in the presence of bulk fluid motion. Convection is classified as natural (or free) and forced convection depending on how the fluid motion is initiated. In natural convection, any fluid motion is caused by natural means such as the buoyancy effect, i.e. the rise of warmer fluid and fall the cooler fluid. Whereas in forced convection, the fluid is forced to flow over a surface or in a tube by external means such as a pump or fan.

\subsection{Flows in Tubes:}

Liquid or gas flow through pipes or ducts is commonly used in practice in heating and cooling applications. The fluid in such applications is forced to flow by a fan or pump through a tube sufficiently long to accomplish the desired heat transfer.

General Considerations: The fluid velocity in a tube changes from zero at the surface to a maximum at the tube center. In fluid flow, it is convenient to work with an average or mean velocity which remains constant in incompressible flow when the cross sectional area of the tube is constant. The value of mean velocity is determined from the conservation of mass principle.

$$
\dot{m}=\rho A V_{m}
$$

Here $\rho$ is the density of the fluid and A is the cross sectional area.

When a fluid is heated or cooled as it flows through a tube, the temperature of a fluid at any cross section changes from $\mathrm{T}_{\mathrm{s}}$ at the surface of the wall at a cross section to some maximum(or minimum in case of heating) at the tube center. In fluid flow it is convenient to work with an average or mean temperature $\mathrm{T}_{\mathrm{m}}$ that remains constant at a cross section. The mean temperature will change in the flow direction, however, whenever the fluid is heated or cooled.

The value of mean temperature is determined from the requirement of law of conservation of energy principle be satisfied. That is the energy transported by a fluid through a cross section in actual flow will be equal to the energy that 
would be transported through the same cross section if the fluid were at a constant temperature $\mathrm{T}_{\mathrm{m}}$.

$$
E_{\text {fluid }}=\dot{m} C_{p} T_{m}
$$

Where $C_{p}$ is the specific heat of the fluid and $\dot{m}$ is the mass flow rate. The product $\dot{m} C_{p} T_{m}$ at any cross section along the tube represents the energy flow with the fluid at that cross section. The conservation of energy equation for the study flow of a fluid in a tube can be expressed as

$$
\dot{Q}=\dot{m} C_{p}\left(T_{e}-T_{i}\right)
$$

Where $T_{i}$ and $T_{i}$ are mean fluid temperatures at the inlet and exit of the tube, respectively, and $\dot{Q}$ is the rate of heat transfer to or from the fluid. The temperature of a flowing fluid remains constant in the absence of any interactions through the wall of the tube.

The thermal conditions at the surface of a tube can usually be approximated with reasonable accuracy to be constant surface temperature or constant surface heat flux. For example the constant surface temperature condition realised when a phase change process such as boiling or condensation occurs at the outer surface of a tube. The constant heat flux condition is realised when the tube is subjected to radiation or electric resistance heating uniformly from all directions.

The convection heat flux at any location on the tube can be expressed as

$$
\dot{q}=h\left(T_{s}-T_{m}\right)
$$

Where $\mathrm{h}$ is the local heat transfer coefficient and $T_{s}$ and $T_{m}$ are the surface and the mean fluid temperatures at that location. Note that the mean fluid temperature of the fluid $T_{m}$ of a fluid fluid flowing in a tube must change during heating or cooling. Therefore, when $\mathrm{h}=$ constant, the surface temperature $T_{s}$ must change when $\dot{q}_{s}=$ constant, and the surface heat flux $\dot{q}_{s}$ must change when $T_{s}=$ constant. Thus we may have either $T_{s}=$ constant or $\dot{q}_{s}=$ constant at the surface of a tube, but not both.

\subsection{Constant Heat Flux:}

In the case of $\dot{q}_{s}=$ constant, the rate of heat transfer can be expressed as

$$
\dot{Q}=\dot{q}_{s} A=\dot{m} C_{p}\left(T_{s}-T_{i}\right)
$$

The mean fluid temperature at the tube exit becomes

$$
T_{e}=T_{i}+\frac{\dot{q}_{s} A}{\dot{m} c_{p}}
$$

Note that the mean fluid temperature increases linearly in the flow direction in the case of constant surface heat flux, since the surface area increases linearly in the flow direction. The surface temperature in this case can be determined from

$$
\dot{q}=h\left(T_{s}-T_{m}\right)
$$

Note that when $\mathrm{h}$ is constant $T_{s}-T_{m}=$ constant, and thus the surface temperature will also increase linearly in the flow direction. This is true when the variation of the specific heat
$C_{p}$ with $\mathrm{T}$ is disregarded and $C_{p}$ is assumed to remain constant.

\section{CFD ANALYSIS}

\subsection{Governing equations:}

In this study, the single-phase model has been used to solve the respective category problems. It is important to set the governing equations (continuity, momentum, and energy) to complete the CDF analysis of the rib-groove channel. The phenomenon under consideration is governed by the steady two-dimensional from of the continuity, the time-averaged incompressible Navier-Stokes equations and energy equation. The methodology used to solve these governing equations will be described in the following section.

\subsection{Standard $k-\in$ model:}

In the Cartesian tensor system these equations can be written as [19]:

Continuity equation:

$$
\frac{\partial\left(\rho u_{i}\right)}{\partial x_{i}}=0
$$

Momentum equation:

$$
\begin{aligned}
& \frac{\partial\left(\rho u_{i} u_{j}\right)}{\partial x_{i}}=-\frac{\partial p}{\partial x_{i}}+\frac{\partial}{\partial x_{j}}\left\lfloor\mu \left(\frac{\partial u_{i}}{\partial x_{j}}+\right.\right. \\
& \left.\left.\frac{\partial u_{j}}{\partial x_{i}}\right)\right\rfloor+\frac{\partial}{\partial x_{j}}\left(-\rho \overline{u_{\iota} \dot{u}_{j}}\right.
\end{aligned}
$$

Energy equation:

$$
\frac{\partial\left(\rho u_{i} T\right)}{\partial x_{i}}=\frac{\partial}{\partial x_{j}}\left(\left(\Gamma+\Gamma_{t}\right) \frac{\partial T}{\partial x_{j}}\right)
$$

Where $\Gamma$ and $\Gamma_{t}$ are molecular thermal diffusivity and turbulent thermal diffusivity, respectively and are given by

$$
\Gamma=\frac{\mu}{P r}, \quad \Gamma_{t}=\frac{\mu_{t}}{P r_{t}}
$$

The turbulent viscosity term $\mu_{t}$ is to be computed from an appropriate turbulence model. The expression for the turbulent viscosity is given as

$$
\mu_{t}=\rho C_{\mu k} \frac{k^{2}}{\varepsilon}
$$

The Reynolds number, the Nusselt number, and the friction factor are expressed by the following relations [1]

$$
\begin{gathered}
R e=\frac{U_{a v} d}{\vartheta} \\
N u_{a v}=\frac{\dot{q} d}{\left(T_{w}-T_{b}\right) k_{f}}
\end{gathered}
$$


Where: Tw and $\mathrm{Tb}$ represent the wall temperature and bulk temperature, respectively. To attain accurate prediction in the rib-groove channel, the standard $\mathrm{k}-\varepsilon$ turbulence model selected. To evaluate the pressure field, the pressure-velocity coupling algorithm SIMPLE was selected.

\subsection{Physical model:}

Schematic diagrams of rib-groove channel for geometrical model and four cases are shown in Fig. 2.1 geometrical model Fig. 2.2 Triangular Rib-Trapezoidal groove

Fig. 2.3 Triangular rib-Triangular groove Fig. 2.4 Trapezoidal rib-Triangular groove Fig. 2.5 Trapezoidal Rib-Trapezoidal groove. Both the height and length of the rib-groove channel are fixed. The following range of height and width are going to be studied:

1. Channel height (D): $60 \mathrm{~mm}$.

2. Channel width (W): $20 \mathrm{~mm}$.

3. Rib and groove height $(\mathrm{H}): 10 \mathrm{~mm}$.

4. Rib and groove width (W): $20 \mathrm{~mm}$.

The length of each adiabatic wall section before and after the test section is set to be $200 \mathrm{~mm}$. As shown in Fig. 2.1 the left side is velocity inlet and the right side is pressure outlet, the up wall is uniform heat flux $\mathrm{q}=10,000 \mathrm{w} / \mathrm{m} 2$, and the down wall is symmetry.

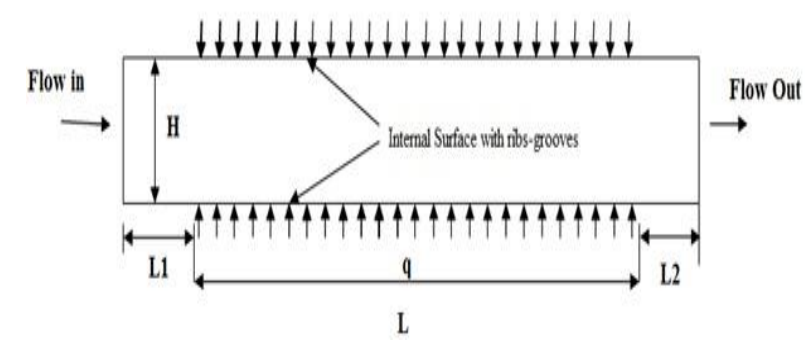

Fig.2.1.Geometric model

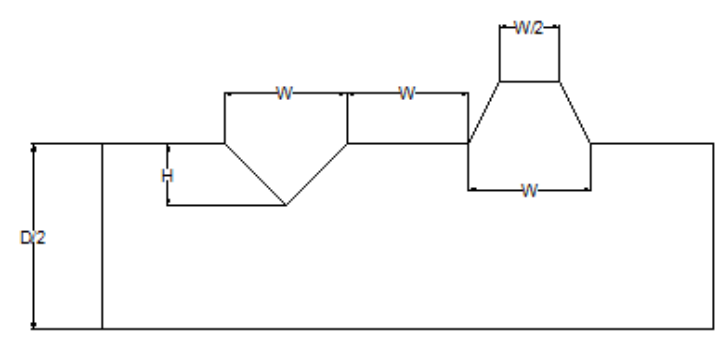

Fig.2.2.Triangular rib-Trapezoidal groove

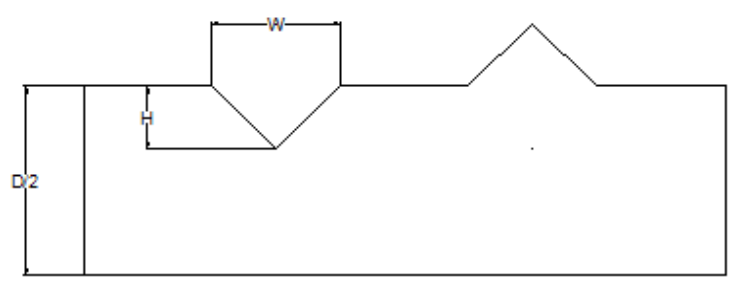

Fig.2.3.Triangular rib-Triangular groove

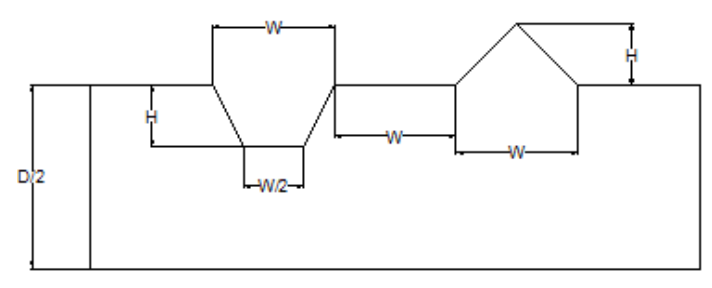

Fig.2.4.Trapezoidal rib-Triangular groove

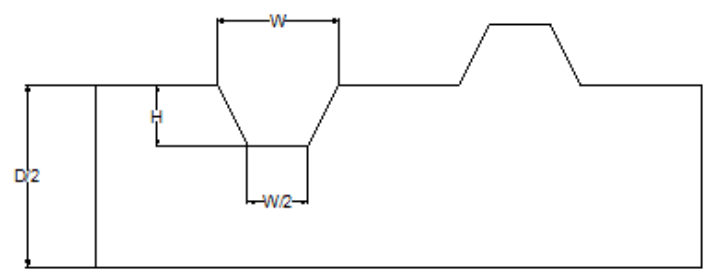

Fig.2.5.Trapezoidal rib-Trapezoidal groove

\subsection{Boundary conditions:}

The boundary conditions for this study are specified for the computational domain as shown in Fig. 2.2 to 2.5. These figures show the general rib-groove channel model selected from this study, whose bottom wall symmetry and top wall is subject to heat flux while the left side is velocity inlet and the right side is pressure outlet. The turbulence model is very important to accommodate the flow behaviour of each application. At the inlet, uniform velocity profile has been imposed. The turbulence intensity was kept at $5 \%$ at the inlet. The solutions are considered to be converged when the normalized residual valuesreach $10^{-6}$ for all variables.

\subsection{Grid independence test:}

The grid generation plays a vital role in any analysis. A proper mesh provides us with approximate solutions to the partial differential equations. The mesh can be coarse or fine depending on the operating condition specifically the Reynolds number. In this section, grid independence test is carried out to obtain the most suitable mesh faces size for particular geometry. In this study, five mesh faces are considered, which are 131463,153256,168791,183562, and 215288 at $\mathrm{Re}=20,000$. All five mesh faces are used to plot the surface Nusselt number of top wall of rib-groove channel on the same XY plot. The discretization grid is structured and uniform. All the five mesh faces have been similar results of Nusselt number. However, anyone of the five faces can be used. In this case, mesh faces(131463)has been used as it is the best in the terms of both the accuracy and computational time. In fact, grid size with more nodes would provide better accuracy in the terms of the results but with increasing density of the cells would make the computational time longer.

\subsection{Code validation:}

Code validation is very important step in any numerical work in order to ensure that they are validated numerical code with other previous work, and it is ready for runs. It is not only important to get a high accuracy of any numerical code, but also to get a better understanding of the capabilities and limitations. The comparison of the present results for smooth channel Nusselt number is validated with the Dittus Boelters equation. 


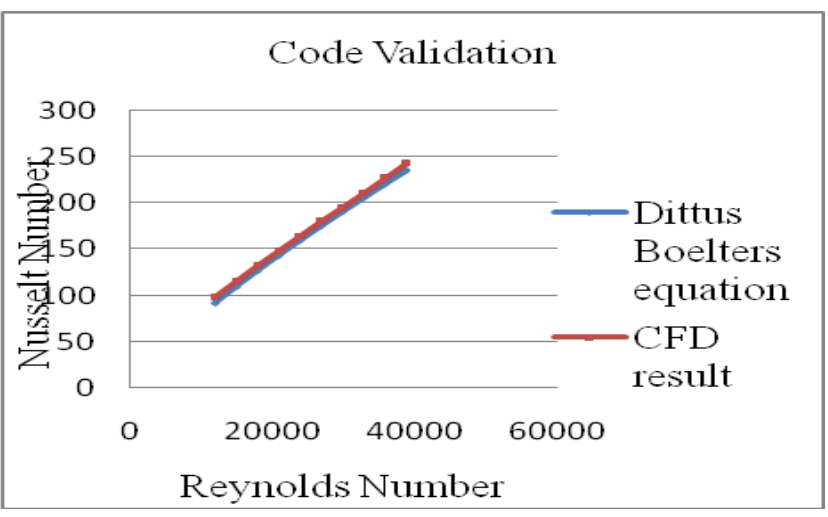

Fig.2.6.Comparison of present work with previous results

\section{NANO FLUIDS}

\subsection{Thermo physical properties of nano fluids:}

In order to carry out simulations for nano fluids, the thermal properties of nanofluids must be calculated first. The nano particles being used are $\mathrm{Al}_{2} \mathrm{O}_{3}, \mathrm{SiO}_{2}, \mathrm{ZnO}$. The effective properties of mass density, specific heat, thermal conductivity, and viscosity are actually calculated according to the mixing theory. The density of nanofluid, $\rho n f$ can be obtained from the following equation [1]

$$
\rho_{n f}=(1-\emptyset) \rho_{f}+\emptyset \rho_{n p}
$$

The effective heat capacity at constant pressure of nano fluid, $(\rho \mathrm{Cp}) \mathrm{nf}$ can be calculated from the following equation[1]

$$
\left(\rho C_{p}\right)_{n f}=(1-\emptyset)\left(\rho C_{p}\right)_{f}+\emptyset\left(\rho C_{p}\right)_{n p}
$$

By using Brownian motion of nano particles in rib-groove channel, the effective thermal conductivity can be obtained by using the following mean empirical correlation [1]

$$
\begin{gathered}
k_{\text {eff }}=k_{\text {static }}+k_{\text {Brownian }} \\
k_{\text {static }}=k_{f}\left[\frac{\left(k_{n p}+2 k_{f}\right)-2 \emptyset\left(k_{f}-2 k_{n p}\right)}{\left(k_{n p}+2 k_{f}\right)+\emptyset\left(k_{f}+2 k_{n p}\right)}\right] \\
k_{\text {brownian }}=5 \times 10^{4} \beta \emptyset \rho_{f} C_{p f} \sqrt{\frac{K T}{2 \rho_{n p} d_{n p}}} f(T, \emptyset)
\end{gathered}
$$

Where Boltzmann constant: $\mathrm{K}=1.3807 \times 10^{-23} \mathrm{~J} / \mathrm{K}$

Modelling $f(T, \emptyset)$

$$
\begin{aligned}
f(T, \emptyset)= & \left(2.8217 \times 10^{-2} \emptyset\right. \\
& \left.+3.917 \times 10^{-3}\right)\left(\frac{T}{T_{0}}\right)-3.0669 \times 10^{-2} \emptyset-3.391123 \times 10^{-3}
\end{aligned}
$$

For $1 \% \leq \emptyset \leq 4 \%$ and $300 k<T>325 k$

The effective viscosity can be obtained by using the following mean empirical correlation

$$
\begin{gathered}
\mu_{e f f}=\mu_{f} \frac{1}{\left(1-34.87\left(\frac{d_{p}}{d_{f}}\right)^{-0.3} \times \emptyset^{1.03}\right.} \\
d_{f}=\frac{6 M}{N_{f} \pi \rho_{f o}}
\end{gathered}
$$

where: $\mathrm{M}$ is the molecular weight of base fluid, $\mathrm{N}$ is the Avogadro number $6.022 \times 10^{23} \mathrm{~mol}^{-1}, \rho_{f o}$ is the mass density of the base fluid calculated at temperature $\mathrm{T}_{0}=293 \mathrm{~K}$.

Table no.1 shows The values of $\beta$ for different particles [1]:

\begin{tabular}{|l|l|l|l|}
\hline $\begin{array}{l}\text { Type of } \\
\text { particles }\end{array}$ & \multicolumn{1}{|c|}{$\boldsymbol{\beta}$} & $\begin{array}{l}\text { Concentration } \\
(\%)\end{array}$ & Temperature(K) \\
\hline $\mathrm{A} 12 \mathrm{O} 3$ & $\begin{array}{l}8.4407(100 \phi)^{-} \\
1.07304\end{array}$ & $1 \% \leq \varphi \leq 10 \%$ & $298 \mathrm{~K} \leq \mathrm{T} \geq 363 \mathrm{~K}$ \\
& $\begin{array}{l}1.9526(100 \phi)^{-} \\
\mathrm{SiO} 2\end{array}$ & $1 \% \leq \varphi \leq 10 \%$ & $298 \mathrm{~K} \leq \mathrm{T} \geq 363 \mathrm{~K}$ \\
& $\begin{array}{l}8.4494 \\
\mathrm{ZnO}\end{array}$ & & \\
& & & \\
\hline
\end{tabular}

Table no.2 shows The thermo physical properties of base fluid and nano particles at $\mathrm{T}=300 \mathrm{k}$.

\begin{tabular}{|l|l|l|l|l|}
\hline $\begin{array}{l}\text { Thermo- } \\
\text { physicalpro } \\
\text { perties }\end{array}$ & Water & $\mathbf{A l 2 O 3}$ & SiO2 & ZnO \\
\hline $\begin{array}{l}\text { Density, } \\
\text { (kg/m3) }\end{array}$ & 998.2 & 3600 & 2220 & 5600 \\
\hline $\begin{array}{l}\text { Specific } \\
\text { heat,Cp } \\
\text { (J/kg K) }\end{array}$ & 4182 & 765 & 745 & 495.2 \\
\hline $\begin{array}{l}\text { Thermalcon } \\
\text { ductivity,k( } \\
\text { W/mK) }\end{array}$ & 0.6 & 36 & 1.4 & 13 \\
\hline $\begin{array}{l}\text { Viscosity,m } \\
\text { (mpa s) }\end{array}$ & 0.001003 & --- & --- & --- \\
\hline
\end{tabular}

\section{RESULTS}

\subsection{Effect of different volume fractions of nano particles:}

The volume fraction of nanoparticles actually refers to the volume of nano particles constituent divided by the volume of the all constituents of the mixture prior to mixing. Trapezoidal and Triangular rib groove configurations is studied with Reynolds numbers from 20000-40000 and different volume fractions $1 \%$ to $4 \%$ of three nanofluids $\mathrm{Al}_{2} \mathrm{O}_{3}, \mathrm{ZnO}, \mathrm{SiO}_{2}$ and base fluid respectively. Nusselt Number increases with increase of volume fraction $(1 \%-4 \%)$ and Reynolds Number 
(10000-40000). The Nusselt number for volume fraction $4 \%$ is high compared with low volume fractions of nanoparticles in the base fluid. The Nusselt number compared with base fluid is as high as $32 \%$ for Reynolds number 40000 . The Nusselt number increases for nanofluids in the order $\mathrm{Al}_{2} \mathrm{O}_{3}, \mathrm{ZnO}$, and $\mathrm{SiO} 2$

\subsubsection{Triangular rib-Trapezoidal groove:}

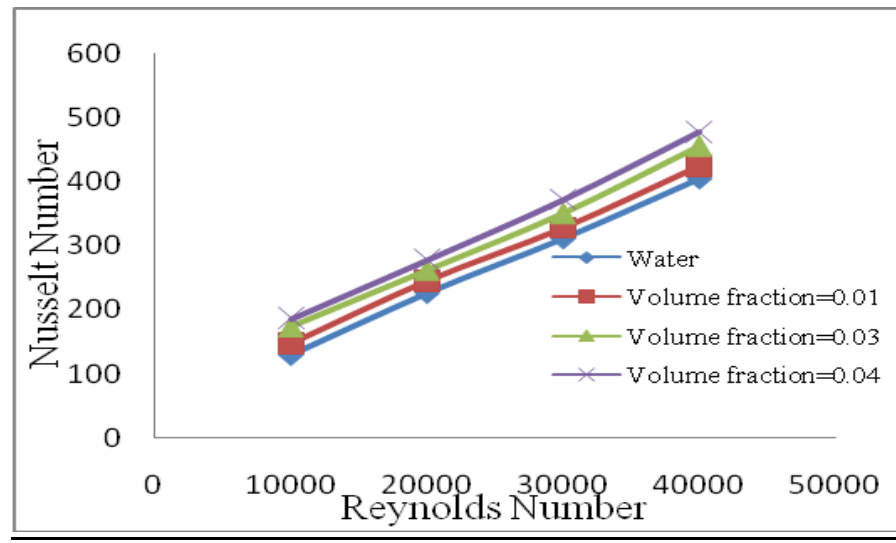

Fig 4.1.1(a) Nusselt Number for channel with different volume fractions of $\mathrm{A} 12 \mathrm{O} 3$ Nanofluid

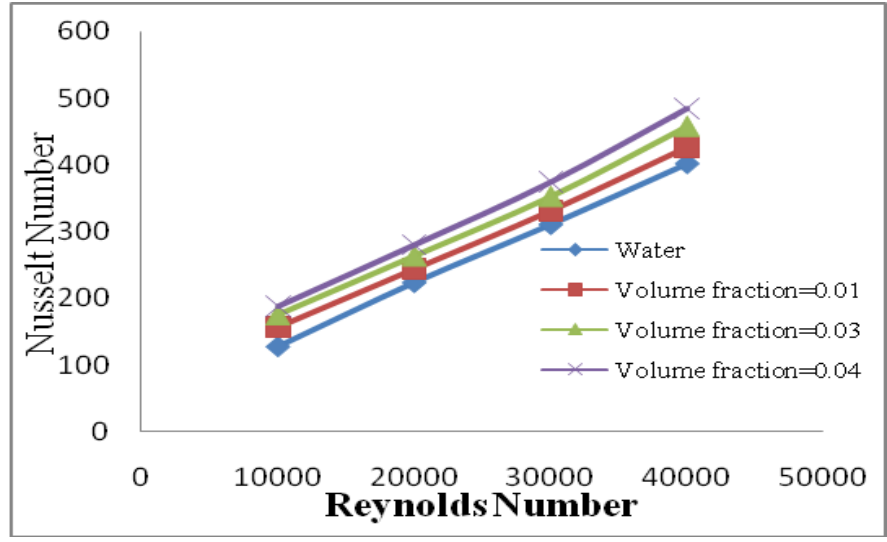

Fig 4.1.1(b).Nusselt Number for channel with different Volume fractions of $\mathrm{ZnO}$ Nanofluid

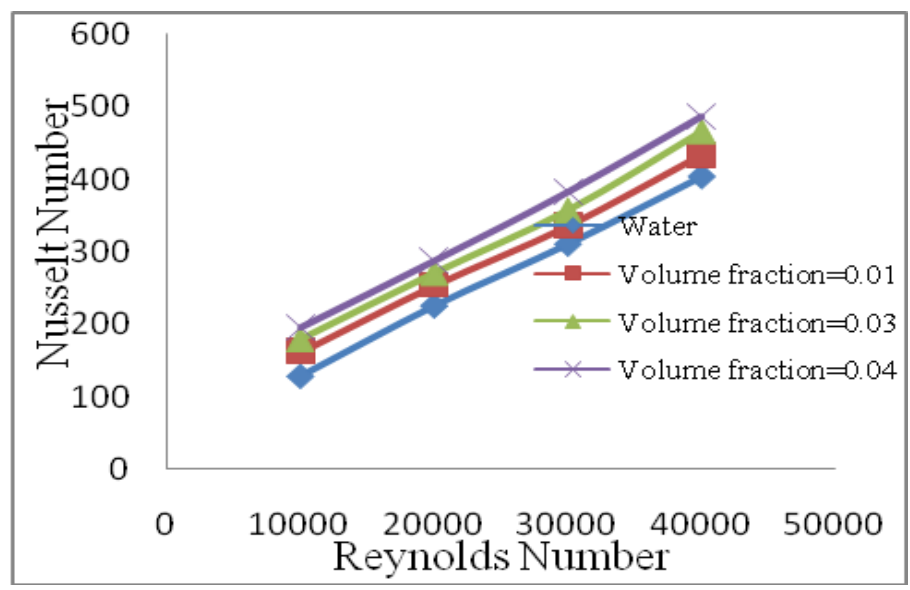

Fig 4.1.1(c) Nusselt Number for channel with different volume fractions of $\mathrm{SiO} 2$ Nanofluid

\subsubsection{Triangular rib-Triangular groove:}

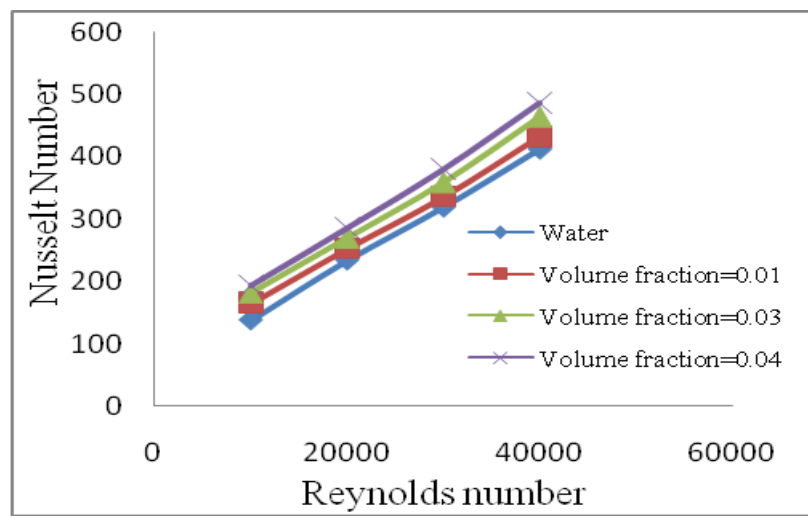

Fig 4.1.2(a).Nusselt Number for channel with different volume fractions of $\mathrm{Al} 2 \mathrm{O} 3 \mathrm{Nanofluid}$

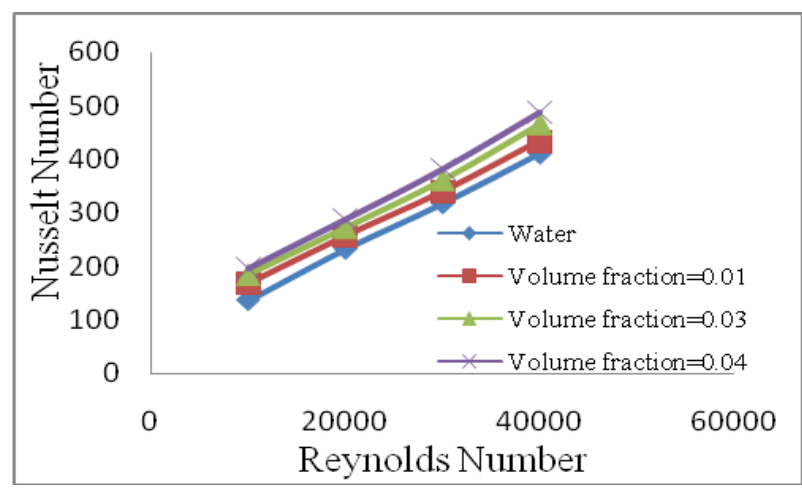

Fig 4.1.2(b).Nusselt number for chasannel with different volume fractions of $\mathrm{ZnO}$ nanofluid

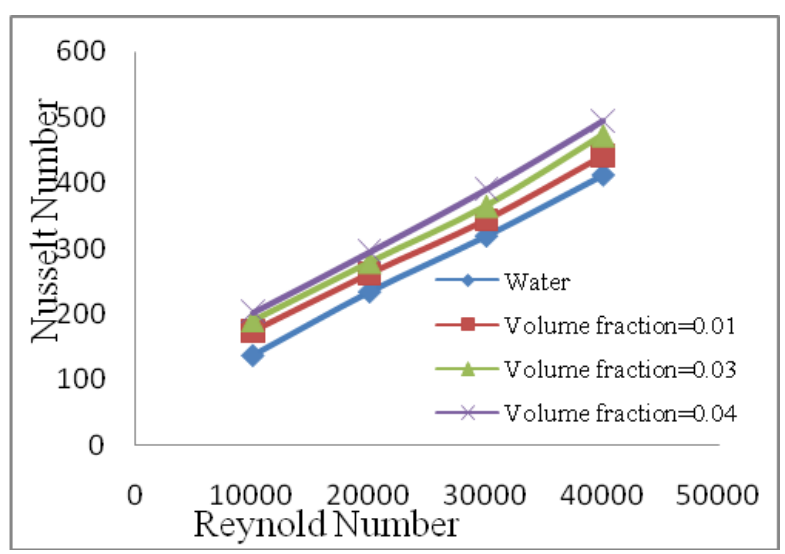

Fig 4.1.2(c).Nusselt number for channel with different volume fractions of $\mathrm{SiO} 2$ nanofluid

\subsubsection{Trapezoidal rib- Triangular groove:}

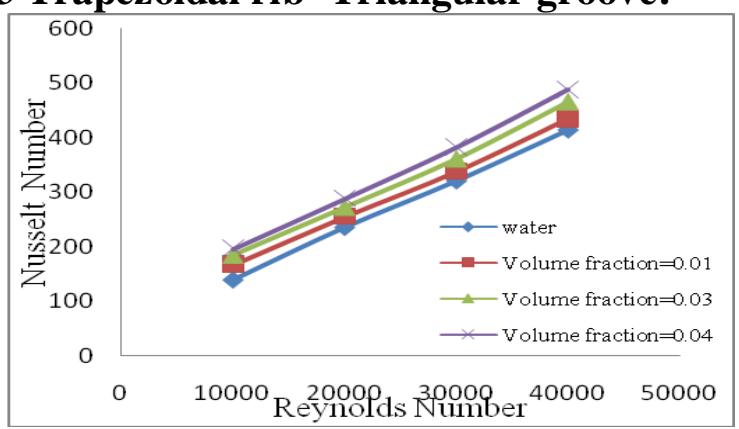

Fig 4.1.3(a).Nusselt Number for channel with different volume fractions of $\mathrm{Al} 2 \mathrm{O} 3$ nano fluid 


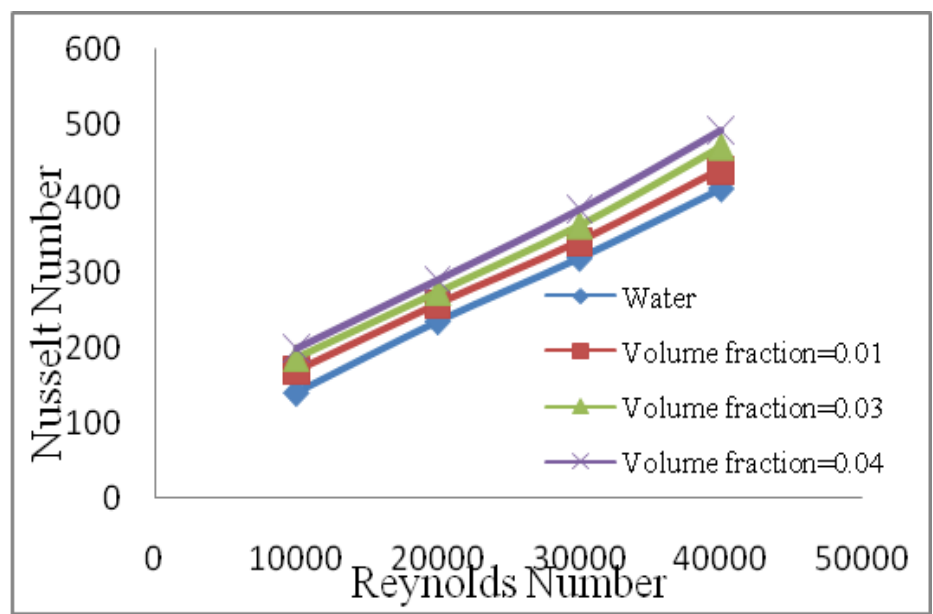

Fig 4.1.3(b)..Nussselt Number for channel with different volume fractions of $\mathrm{ZnO}$ Nano fluid

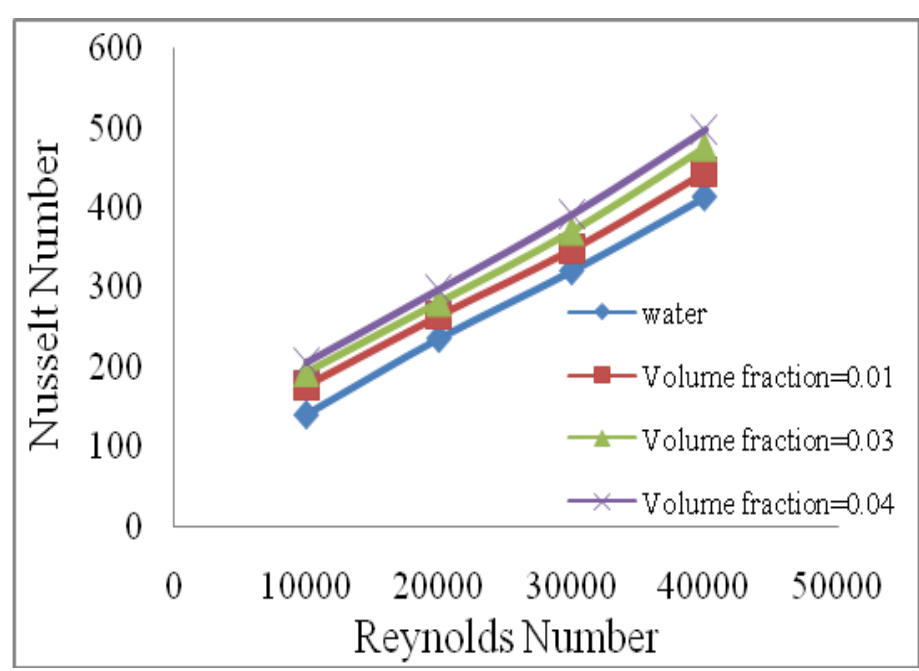

Fig 4.1.3(c)..Nusselt Number for channel with different volume fractions of $\mathrm{SiO} 2$ Nanofluid

\subsubsection{Trapezoidal rib-Trapezoidal groove:}

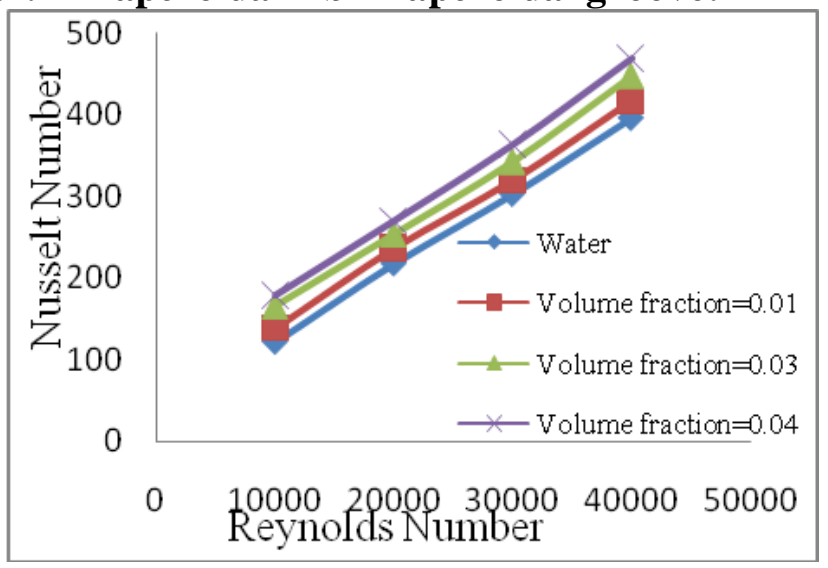

Fig 4.1.4(a)..Nusselt Number for channel with different volume fractions of AL2O3 Nanofluid

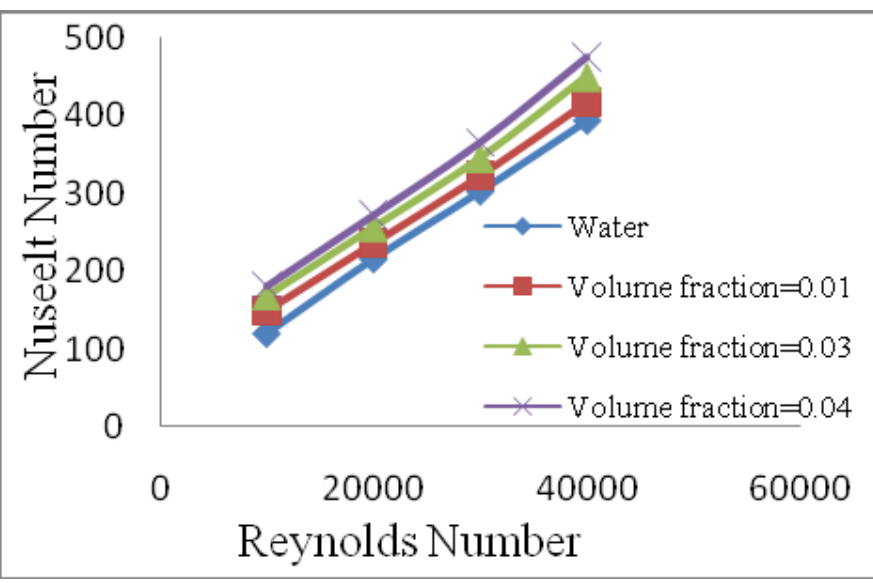

Fig 4.1.4(b)..Nusselt Number for channel with different volume fractions of $\mathrm{ZnO}$ Nano fluid

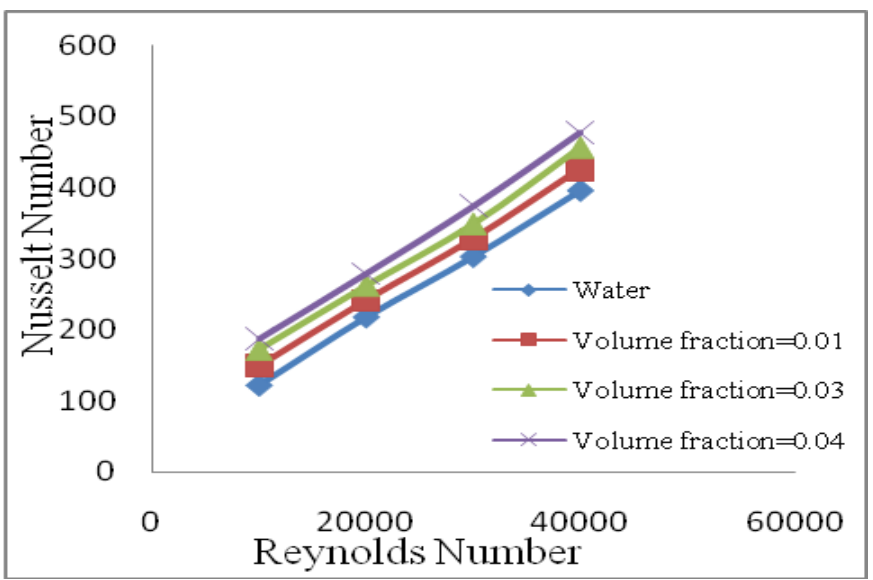

Fig 4.1.4(c).Nusselt Number for channel with different volume fractions of $\mathrm{SiO} 2$ Nanofluid

\subsection{The effect of different types of nanoparticles:}

Three different types of nano particles $\mathrm{Al}_{2} \mathrm{O}_{3} \quad \mathrm{SiO}_{2}$, and $\mathrm{ZnO}$ and pure water as a base fluid are used. The nano particle concentration used in this case is $4 \%$ and the nano particle diameter is $30 \mathrm{~nm}$. The Nusselt number for different nano fluids and different values of Reynolds number are shown It can be seen that the Nusselt number increases with the increase of Reynolds number for all cases. It is observed that all three nano fluids possess higher Nusselt number compared to pure water. These figures show for the different range of Reynolds number, it is clear that nano fluid with $\mathrm{SiO} 2$ has the best heat transfer rate, followed by $\mathrm{Al} 2 \mathrm{O} 3, \mathrm{ZnO}$ and pure water respectively. This phenomenon can be attributed to the fact of the high thermal properties of $\mathrm{SiO} 2$-water compared with the lower thermal properties of other nano fluids types or with pure water. 


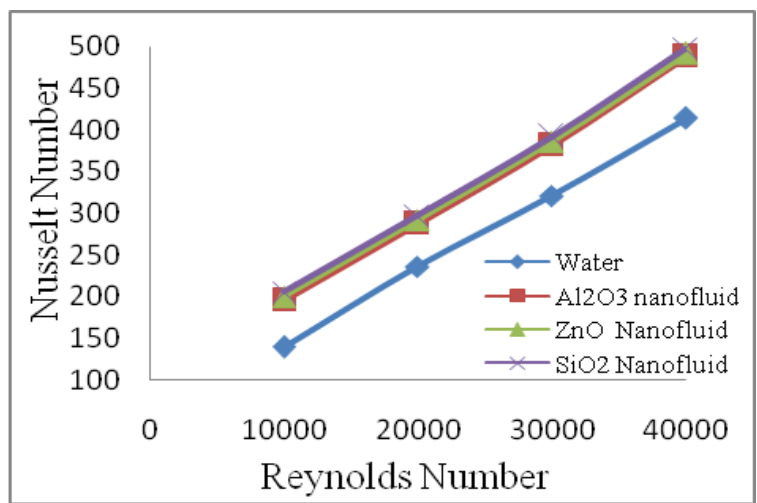

Fig 4.2(a).Nusselt Number for Channel with different Nanofluids and base fluid for Triangular rib-Trapezoidal groove configuration.

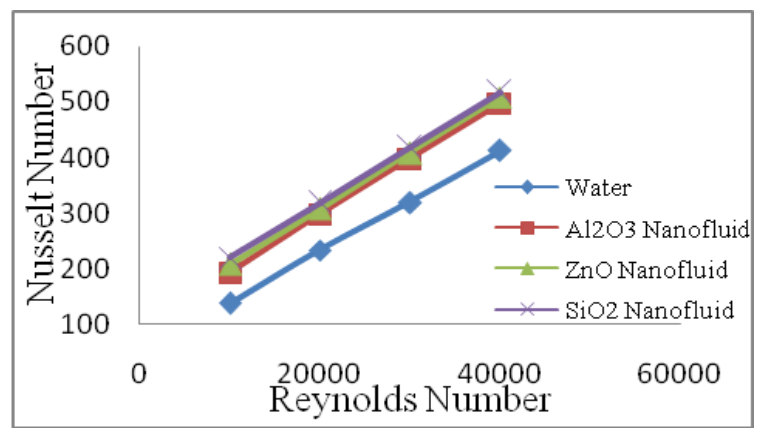

Fig 4.2(b).Nusselt Number for Channel with different Nanofluids and base fluid for Triangular rib-

Triangular groove configuration.

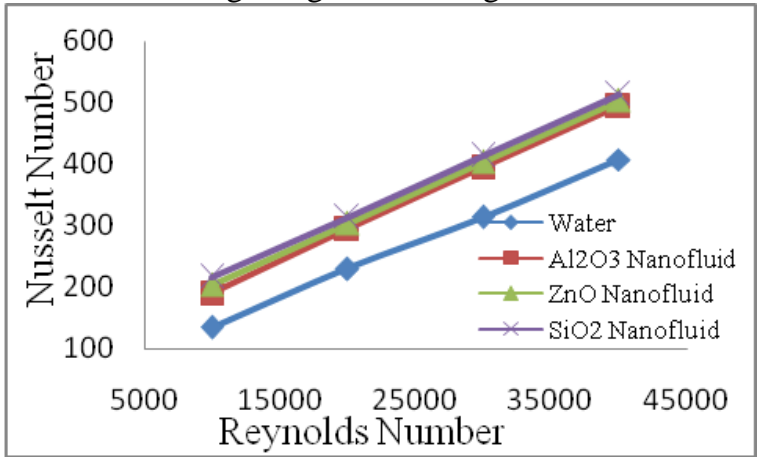

Fig 4.2(c).Nusselt Number for Channel with different Nano fluids and base fluid for Trapezoidal rib-Triangular groove configuration.

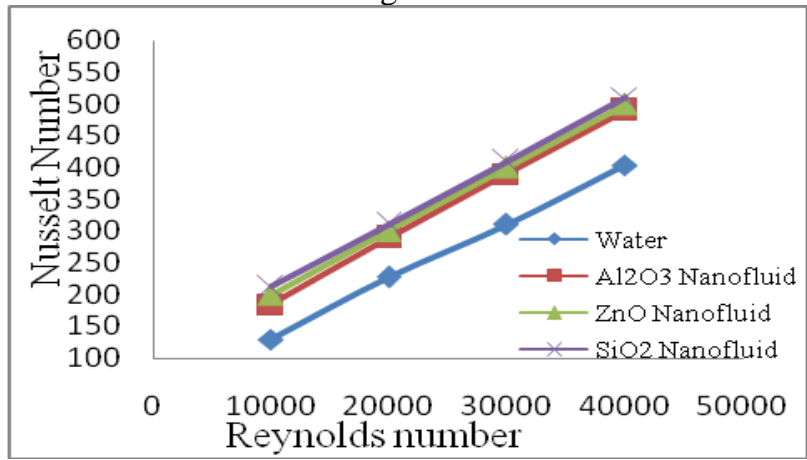

Fig 4.2(d).Nusselt Number for Channel with different Nano fluids and base fluid for Trapezoidal rib-Trapezoidal groove configuration.

\subsection{The effect of different nano particles diameters:}

In this study used $\mathrm{SiO} 2-$-water as a working fluid with fixed other parameters such as volume fraction $4 \%$ except Reynolds number was in the range of 10000-40,000.The range of nano particles diameter is $30-70 \mathrm{~nm}$. As shown in Fig.4.3(a) to 4.3(d), the results of Nusselt number increase with decreasing the nano particles diameter. This can be attributed to an increment of the thermal conductivity due to nano particles diameter decreases. This finding is due to the effects of Brownian motion at small nano particle diameters, resulting in high thermal conductivity of nano fluids Therefore, for SiO2water nano fluid, the decreasing nano particle size increases the effect of aggregation, nano layer formations, Brownian motion, and energy transfer. It is concluded that by using smaller diameter of nano particles will lead to get better heat transfer enhancement. In all cases, it can be observed that Nusselt number increases with increasing Reynolds number for all nano particles diameter, dp leading to better heat transfer.

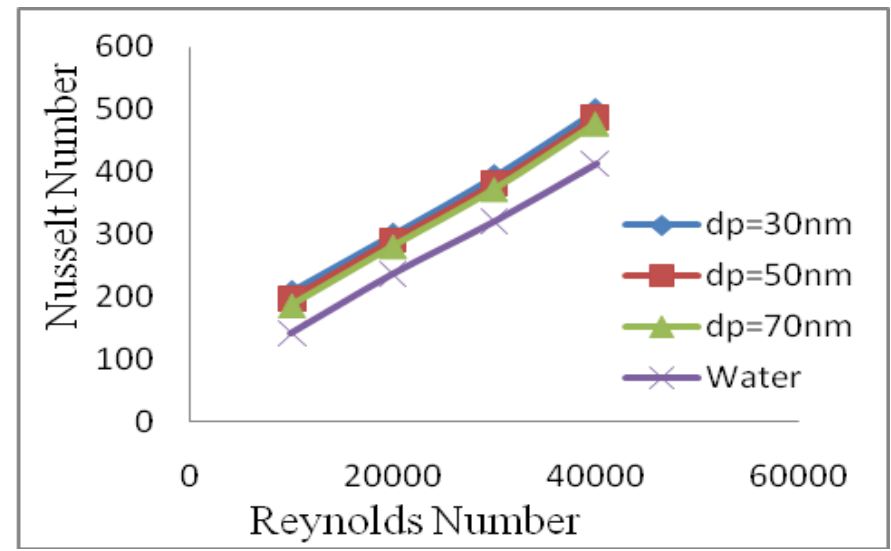

Fig 4.3(a).Nusselt Number for Channel with different diameters of nanoparticles for Triangular rib- Trapezoidal groove configuration.

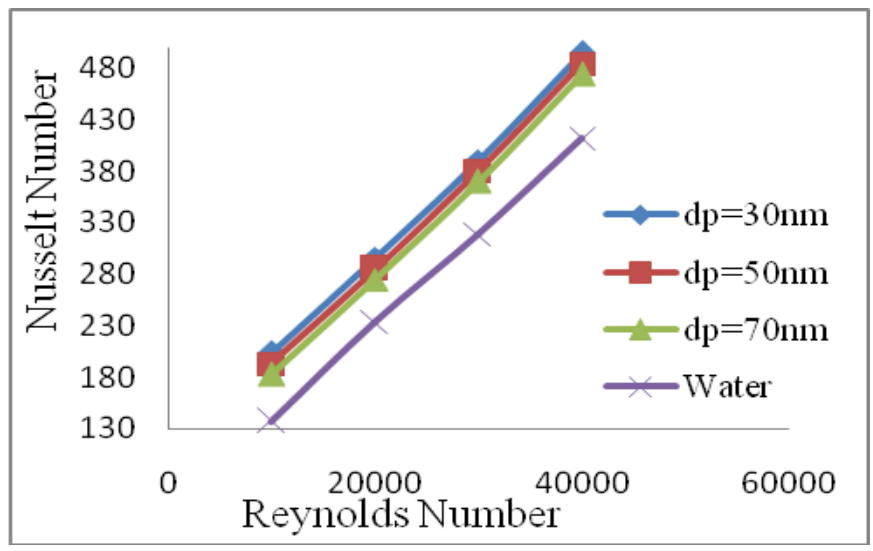

Fig 4.3(b).Nusselt Number for Channel with different diameters of nano particles for Triangular rib-Triangular groove configuration. 


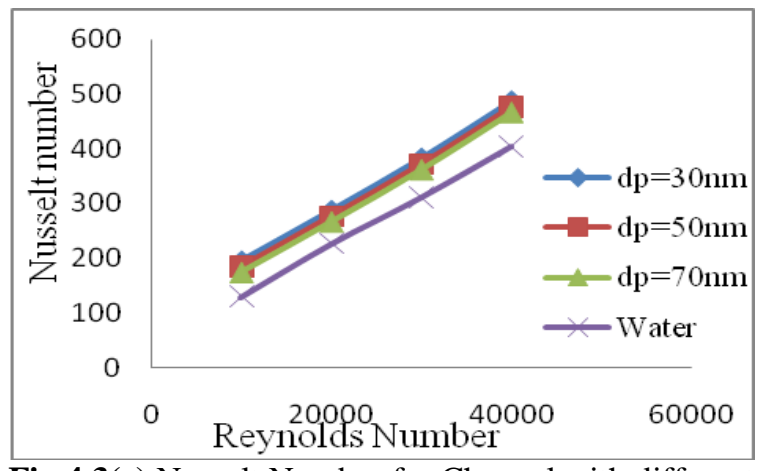

Fig 4.3(c).Nusselt Number for Channel with different diameters of nano particles for Trapezoidal rib-Triangular groove configuration.

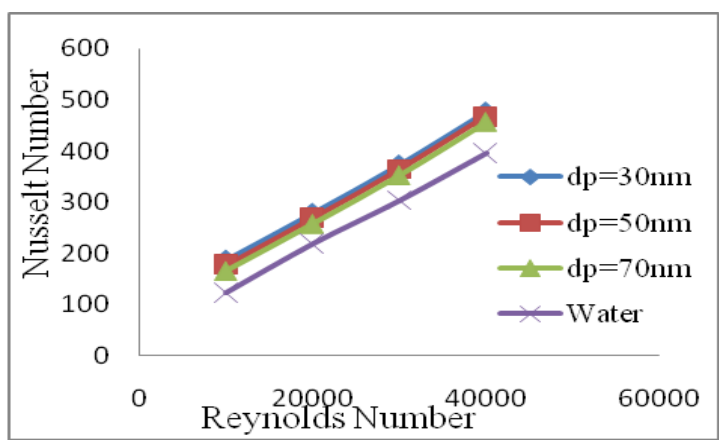

Fig 4.3(d).Nusselt Number for Channel with different diameters of nanoparticles for Trapezoidal rib-Trapezoidal groove configuration.

\subsection{The effect of different rib-groove shapes:}

In this study, the effect of four different rib-grooves shapes(Triangular Rib-Trapezoidal Groove, Triangular ribTriangular groove, Trapezoidal rib-Triangular groove, Trapezoidal rib-Trapezoidal Groove) on thermal and fluid fields were examined. The variation of average Nusselt number with Reynolds number is presented in Fig.4.4 As shown in Fig the average Nusselt number rate increase with the increase of Reynolds number, it can be seen that the all shapes have highest value of Nusselt number compared with smooth channel. The Triangular rib-Trapezoidal groove channel provided the better heat transfer rate among all types of shapes as well as the smooth channel. This is because of a strong mixing of the fluid induced from turbulent flow, leading to higher temperature gradients in these shapes compared to the smooth channel.

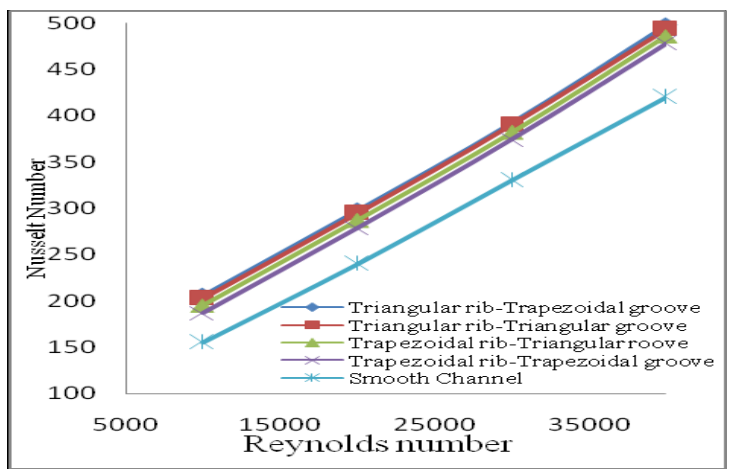

Fig 4.4. Nusselt Number Variation with different rib-groove configurations

\section{CONCLUSION}

Numerical simulation of turbulent forced convection heat transfer through rib-groove channel having different shapes with different type of nano fluids $\left(\mathrm{Al}_{2} \mathrm{O}_{3}, \mathrm{ZnO}, \mathrm{SiO}_{2}\right.$ with water), volume fraction of nano particles in the range of $1 \%$ to $4 \%$, nano particle diameter in the range of 30 to $70 \mathrm{~nm}$, and the Reynolds number in the range of 10,000 to 40,000 has been carried out. According to obtained results, the conclusions can be drawn as follows.

* By changing the rib-groove shapes on thermal and fluid fields, the results show that Triangular rib-Trapezoidal groove gives the highest nusselt number in comparision with other types of rib-groove shapes.

* By changing the types of nano particles $\left(\mathrm{Al}_{2} \mathrm{O}_{3}, \mathrm{ZnO}\right.$, $\mathrm{SiO}_{2}$ ), the results show that $\mathrm{SiO}_{2}$ gives the highest nusselt number followed by $\mathrm{ZnO}, \mathrm{Al}_{2} \mathrm{O}_{3}$ respectively while pure water gives the lowest value of nusselt number.

* The Nusselt number increased with increasing the volume fraction of nano particles.

* The Nusselt number increases gradually when decreasing the nano particle diameter.

* The Nusselt number increases gradually by increasing the Reynolds number, Re in the range of 10,000 -40,000.

\section{REFERENCES:}

1. Azher M.Abed, K.Sopian "Enhance heat transfer in the channel with V-shaped wavy lower plate using liquid nanofluids" Case Studies in Thermal Engineering 5(2015)13-23

2. TANG Xinyi, ZHU DongSheng" Experimental and Numerical study on heat transfer Enhancement of a rectangular channel with discontinuous crossed ribs and grooves" Chinese Journal of Chemical Engineering. 20(2)220-230(2012)

3. R. Kamali , A.Binesh, The importance of rib shape effects on the local heat transfer and flow friction characteristics of square ducts with rib bed internal surfaces, Int.Commun. Heat Mass Transf.35(2008)1032-1040.

4. K.Bilen,M.Cetin,H.Gul,T.Balta,The investigation of groove geometry effect on heat transfer for internally grooved tubes,Appl.Therm.Eng.29 (2009)753-761.

5. PinganL.,YeG.,HairongM.,LiuH.Numerical simulation of heat transfer and resistance pattern in channels with different ribs. Computer Design and Applications (ICCDA), 2010International Conferenceon: IEEE; 2010.p.V3-507-V3-11.

6. S.Eiamsa-Ard,P.Promvonge,Thermal characteristics of turbulent Rib-Grooved channel flows,Int.Commun.HeatMassTransf.36(2009)705711.

7. A.R.Jaurker,J.S.Saini,B.K.Gandhi,Heat transfer and friction characteristics of rectangular solar air heater duct using Rib-Grooved artificial roughness, Sol. Energy80(2006)895-907. 
8. Veysel Ozceyhan and Sibel Gunusstudied Heat transfer enhancement in a tube using triangular ribs ASME2008 Heat transfer Volume 3

9. O.Manca,S.Nardini,D.Ricci,Numerical study of air forced convection in a rectangular channel provided with Ribs, Front. Heat Mass Transf.(2011).

10. C.Thianpong,T.Chompookham,S.Skullong,P.Promvo nge,Thermal characterization of turbulent flow in a channel with isosceles triangular,Int. Commun. Heat Mass Transf.36 (2009)712-717.

11. C.T.Nguyen,G.Roy,C.Gauthier,N.Galanis,Heat transfer enhancement usingAl2O3-wate rnano fluid for an electronic liquid cooling system,Appl. Therm. Eng.27(2007)1501-1506.

12. M.-S. Liu, Lin MC-C, C.Y.Tsai,C.10.Wang,Enhancement of thermal conductivity with $\mathrm{Cu}$ for nanofluids using chemical reduction method, Int .J.Heat Mass Transf.49(2006)3028-3033

13. H.Mohammed, A.Al-Shamani, J.Sheriff, Thermal and hydraulic characteristics of turbulent nanofluids flow in a Rib-Groove channel,Int. Commun. Heat Mass Transfer. 39(2012)1584-1594.

14. A.R.Ahmadi, A.Zahmatkesh, M.Hatami, D.D.Ganji,A comprehensive analysis of the flow and heat transfer for a nanofluid over an unsteady stretching flat plate, Powder Technol. 258(2014)125133. 